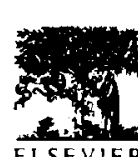

\title{
Observations of dynamic strain aging in polycrystalline NiAl
}

\author{
M. L. Weaver, ${ }^{a}$ R. D. Noebe ${ }^{b} \&$ M. J. Kaufman ${ }^{c}$ \\ ${ }^{a}$ Center for Nonlinear and Nonequilibrium Aeroscience, Florida A\&M University. Tallahassee, FL 32310, and Department of \\ Mechanical Engineering, FAMU-FSU College of Engineering. Florida A\&M University-Florida State University. Tallahassee, \\ Florida 32310, USA \\ ${ }^{h}$ NASA Lewis Research Center, Cleveland, Ohio 44135, USA \\ 'Department of Materials Science and Engineering, University of Florida, Gainesville, Florida 3261I, USA
}

(Received 20 August 1995; accepted 12 February 1996)

\begin{abstract}
Dynamic strain aging has been investigated at temperatures between 77 and $1100 \mathrm{~K}$ in eight polycrystalline $\mathrm{NiAl}$ alloys. The $0.2 \%$ offset yield stress and work hardening rates for these alloys generally decreased with increasing temperature. However. local plateaus or maxima were observed in conventional purity and carbon doped alloys at intermediate temperatures $(600-900 \mathrm{~K})$. This anomalous behavior was not observed in low interstitial high-purity, nitrogen doped, or in titanium doped materials. Low or negative strain rate sensitivities (SRS) were also observed in all eight alloys in this intermediate temperature range. Coincident with the occurrence of negative SRS was the occurrence of serrated flow in conventional purity alloys containing high concentrations of $\mathrm{Si}$ in addition to $\mathrm{C}$. These phenomena have been attributed to dynamic strain aging (DSA). Chemical analysis of the alloys used in this study suggests that the main species causing strain aging in polycrystalline $\mathrm{NiAl}$ is $\mathrm{C}$ but indicate that residual $\mathrm{Si}$ impurities can enhance the strain aging effect. C 1996 Elsevier Science Limited.
\end{abstract}

Keywords: A. nickel aluminides, based on NiAl, B. mechanical properties at high temperatures, strain aging.

\section{INTRODUCTION}

In refs $1-5$, it was shown that polycrystalline $\mathrm{NiAl}$ alloys, in the presence of sufficient solute levels, are subject to the phenomenon of strain aging. Strain aging is a common occurrence in metals and alloys ${ }^{6}$ and often manifests itself as: (1) sharp yield points, (2) serrated stress-strain curves, (3) strain rate sensitivity minima, (4) maxima in plots of work hardening rate as a function of temperature, (5) yield stress plateaus or local maxima as a function of temperature, (6) flow stress transients upon changes in strain rate, and (7) reduced tensile elongations over specific temperature/strain rate ranges. A description of these phenomena are provided in refs 7-9. Over the years, most of these aforementioned manifestations of strain aging have been reported to occur in NiAl. ${ }^{1-5,10-21}$ Despite these observations, however, the relative significance of strain aging and its influence on the mechanical properties of ordered intermetallic compounds has been largely ignored.

Consequently, the purpose of this paper is to describe the results of a study of dynamic strain aging (DSA) in polycrystalline NiAl. To accomplish this goal, stoichiometric NiAl polycrystals with differing interstitial contents were studied. In addition, since dilute additions of reactive elements have been reported to retard strain aging in $\mathrm{BCC}$ alloys and in single crystal $\mathrm{NiAl},{ }^{510}$ an $\mathrm{NiAl}$ alloy intentionally doped with $\mathrm{Ti}$ was investigated to analyze the role of a reactive ternary addition on the strain aging behavior of polycrystalline $\mathrm{NiAl}$. These results are then discussed with respect to recent observations of DSA phenomena in NiAl single crystals. ${ }^{5.10} 15.22$

\section{MATERIALS AND METHODS}

The five cast and extruded alloys (i.e. CPNiAl-1, CPNiAl-2, NiAl-100C, NiAl-300C and NiAl-Ti) and the extruded nitrogen-doped powder alloy, $\mathrm{NiAl}-\mathrm{N}$, used to study static strain aging (SSA) and described in a previous paper ${ }^{3}$ were used here. In addition, two more carbon-doped alloys, $\mathrm{NiAl}-100 \mathrm{CO}$ and $\mathrm{NiAl}-$ $300 \mathrm{CO}$, were induction melted and extruded using the techniques described in ref. 3. As before, post 
extrusion chemical analyses of the new ingots were conducted using the techniques deemed the most accurate for the particular elements. The results of these analyses are listed in Table 1. Cylindrical compression specimens and round button-head tensile specimens were ground from the extruded rods so that the gage lengths were parallel to the extrusion direction. Sample dimensions were $3.1 \mathrm{~mm}$ for the tensile gage diameters and $30.0 \mathrm{~mm}$ for the tensile gage lengths, and $3.0 \mathrm{~mm}$ for the compression sample diameters and $6.4 \mathrm{~mm}$ for the lengths. All specimens were electropolished prior to testing in a $10 \%$ perchloric acid-90\% methanol solution that was cooled to $208 \mathrm{~K}$. During some of the compression tests, the strain was measured using a clip on strain gage extensometer attached to a compression cage.

All tensile and compression tests were performed using a screw driven load frame at constant crosshead velocities corresponding to an initial strain rate of $1.4 \times 10^{-4} \mathrm{~s}^{-1}$. Testing was accomplished in two steps. First, the temperature dependence of flow stress was determined by testing all as-extruded alloys in air between 300 and $1200 \mathrm{~K}$ by heating the samples in a clamshell type resistance furnace where temperature gradients were controlled to $\pm 2 \mathrm{~K}$. Tests below room temperature were conducted in compression by cooling the specimens in liquid baths. During this phase of testing, the strain rate sensitivity (SRS) was also determined by increasing the strain rate by a factor of ten from the base strain rate at fixed plastic strain intervals. The quantity extracted from these experiments was the SRS, $s=\Delta \sigma / \Delta \ln \dot{\epsilon}$. Second, alloys exhibiting roomtemperature yield discontinuities after annealing were subjected to SSA tests. A description of the SSA test procedure is provided in refs 2,3 and 5.
Samples for transmission electron microscopy (TEM) were cut from the tested tensile and compression specimens with a low-speed diamond saw and twin jet-electropolished in a solution of $70 \%$ ethanol, $14 \%$ distilled water, $10 \%$ butylcellusolve, and $6 \%$ perchloric acid at $273 \mathrm{~K}, 25 \mathrm{~V}$, and $0.15 \mathrm{~mA}$. TEM examinations were conducted in a modified JEOL $100 \mathrm{C}$ micro-scope operating at an accelerating voltage of $120 \mathrm{kV}$.

\section{RESULTS}

\section{Chemical compositions}

The post-extrusion microstructure of all alloys consisted of fully equiaxed and recrystallized grains with nominal grain sizes of $20 \mu \mathrm{m}$ except for the $\mathrm{NiAl}-\mathrm{N}$ alloy that had a grain size of approximately $5 \mu \mathrm{m}$. The results of chemical analyses of the extruded alloys revealed that, within experimental accuracy, the $\mathrm{Ni}$ and $\mathrm{Al}$ contents of the eight nominally stoichiometric alloys are not significantly different from each other. The major differences between the materials are the addition of 0.3 at $\%$ Ti to NiAl$\mathrm{Ti}$ and the varying carbon and oxygen interstitial levels. Chemical analysis of the new carbon-doped alloys revealed that, in addition to containing the desired levels of carbon, each contained five times as much oxygen as the first set of ingots. As a result, the new ingots were labeled $\mathrm{NiAl}-100 \mathrm{CO}$ and $\mathrm{NiAl}-300 \mathrm{CO}$, respectively.

\section{Tensile properties}

Mechanical tests and strain rate change experiments were conducted in the temperature range of $77-$

Table 1. Chemical compositions of extruded alloys examined in this study

\begin{tabular}{|c|c|c|c|c|c|c|c|c|}
\hline \multirow[b]{2}{*}{ Alloy } & \multicolumn{4}{|c|}{$a t \%$} & \multicolumn{4}{|c|}{ at ppm } \\
\hline & $\mathrm{Ni}$ & Al & $\mathrm{Ti}$ & $\mathrm{Si}$ & C & O & $N$ & $\mathrm{~S}$ \\
\hline $\mathrm{NiAl}-100 \mathrm{CO}$ & $50.0 \pm 0.2$ & $49 \cdot 8 \pm 0.2$ & - & 0.03 & 420 & 1283 & 22 & $<13$ \\
\hline $\mathrm{NiAl}-300 \mathrm{CO}$ & $49.9 \pm 0.2$ & $49 \cdot 8 \pm 0 \cdot 2$ & - & 0.02 & 1072 & 1345 & 34 & $<12$ \\
\hline CPNiAl-1 & $50.1 \pm 0.2$ & $49.7 \pm 0.2$ & - & $0 \cdot 15$ & 147 & $70^{*}$ & $<9$ & $<7$ \\
\hline CPNiAl-2 & $50.1 \pm 0.2$ & $49.8 \pm 0.2$ & $\ldots$ & 0.02 & 186 & 94 & $<9$ & $<7$ \\
\hline $\mathrm{NiAl}-100 \mathrm{C}$ & $49.9 \pm 0.2$ & $50.0 \pm 0.2$ & - & 0.02 & 491 & 180 & $<9$ & $<7$ \\
\hline $\mathrm{NiAl}-300 \mathrm{C}$ & $49.9 \pm 0.2$ & $50 \cdot 0 \pm 0.2$ & - & 0.01 & 1153 & 131 & $<9$ & $<7$ \\
\hline $\mathrm{NiAl}-\mathrm{N}$ & $50.1 \pm 0.2$ & $49.7 \pm 0.2$ & - & 0.02 & 57 & 347 & 904 & $<7$ \\
\hline $\mathrm{NiAl}-\mathrm{Ti}$ & $49.9 \pm 0.2$ & $50 \cdot 0 \pm 0.2$ & 0.03 & 0.00 & 214 & 113 & $<9$ & $<7$ \\
\hline
\end{tabular}

Ni \& Al Analysis performed using wet chemistry/titration techniques, relative accuracy $\pm 1 \%$.

$\mathrm{Ti} \quad$ Analysis perforrned using inductively coupled plasma emission spectroscopy, relative accuracy $\pm 5 \%$.

C \& S Analysis performed on a simultaneous carbon/sulfur determinator, LECO Corp., Model CS-244, relative accuracy $\pm 10 \%$.

$\mathrm{N} \& \mathrm{O}$ Analysis performed on a simultaneous nitrogen/oxygen determinator, LECO Corp., Model TC-136 or Model TC-436, relative accuracy $\pm 10 \%$.

Si Analysis performed on an ultraviolet/visible spectrophotometer, Shimadzu, Model UV-160, relative accuracy $\pm 10 \%$

*The figure of 550 at ppm quoted in earlier papers was in error. 
$1200 \mathrm{~K}$. The temperature-dependent properties (i.e. flow stress, work hardening rate and SRS) are summarized in Figs 1-3. Figure 1 shows the temperature dependence of the flow stress at $0.2 \%$ plastic strain. In agreement with previous studies, ${ }^{20}$ the flow stress generally decreased with increasing temperature. In all alloys except $\mathrm{NiAl}-\mathrm{Ti}$ and $\mathrm{NiAl}-\mathrm{N}$, however, a definite plateau or slight local maximum was observed in the range $750-900 \mathrm{~K}$.

The work hardening characteristics over the 0.2 $1.8 \%$ plastic strain interval have been evaluated from the average work hardening rate, $\theta=(\Delta \sigma / \Delta \epsilon)$, and average work hardening exponent, $n$, as defined by the equation:

$$
\sigma=K \epsilon^{n}
$$

where $K$ is a strength coefficient. ${ }^{23}$ The resulting values for $\theta$ and $n$ have been normalized with respect to the elastic modulus ${ }^{24,25}$ and are summarized in Fig. 2. Much like the $0.2 \%$ yield stress, both $\theta / E$ and $\mathrm{n} / E$ decreased steadily with increasing temperature. All alloys except $\mathrm{NiAl}-\mathrm{Ti}$ and $\mathrm{NiAl}-\mathrm{N}$ exhibited slightly anomalous or local maxima in work hardening behavior in the temperature range $600-700 \mathrm{~K}$.

The temperature dependence of the strain rate sensitivity, $s$, is presented in Fig. 3. The SRS remained
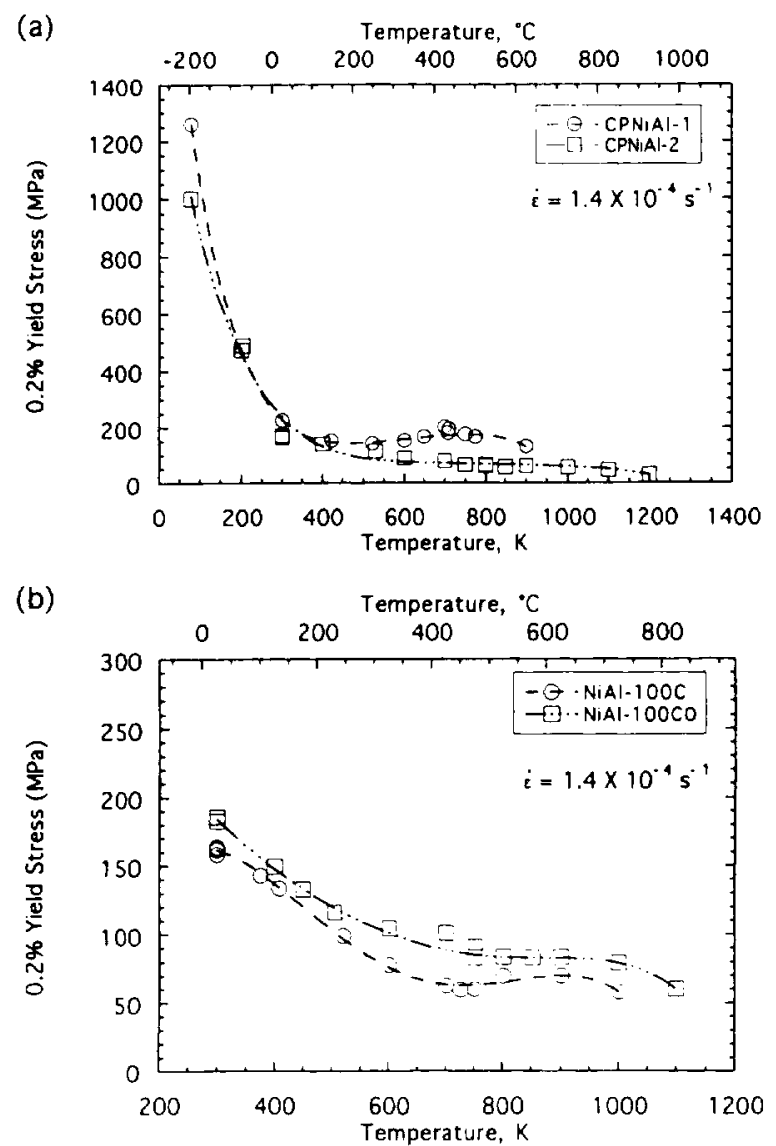

positive for all alloys except CPNiAl-1 which exhibited negative $s$ values between 600 and $700 \mathrm{~K}$. For all alloys distinct minima were observed in the temperature range $750-850 \mathrm{~K}$ with the minima in the carbondoped and higher carbon containing alloys occurring at slightly lower temperatures than in CPNiAl-2 and $\mathrm{NiAl-Ti}$. This behavior is analogous to many softoriented single crystal alloys which also exhibit SRS minima in this regime and which often exhibit negative strain rate sensitivities and serrated flow indicative of DSA. ${ }^{11.13} 15.26 .27$ Serrated flow was only observed in CPNiAl-1 (Fig. 4(a)) and not in any of the other alloys studied here. However, yield stress transients in the form of sharp yield points were consistently observed in the temperature range of the flow stress plateau in all alloys except $\mathrm{NiAl}-\mathrm{Ti}$ upon increasing the strain rate by a factor of ten. Examples of this behavior are illustrated in Fig. 4. These yield stress transients are clearly indicative of DSA.

Limited SSA experiments were conducted on $\mathrm{NiAl}-100 \mathrm{C}$ to determine the influence of strain aging on the formation of a sharp yield point at room temperature. The experimental techniques used are described in refs 2-5 and the results are presented in Fig. 5. These experiments were conclusive in that

(c)
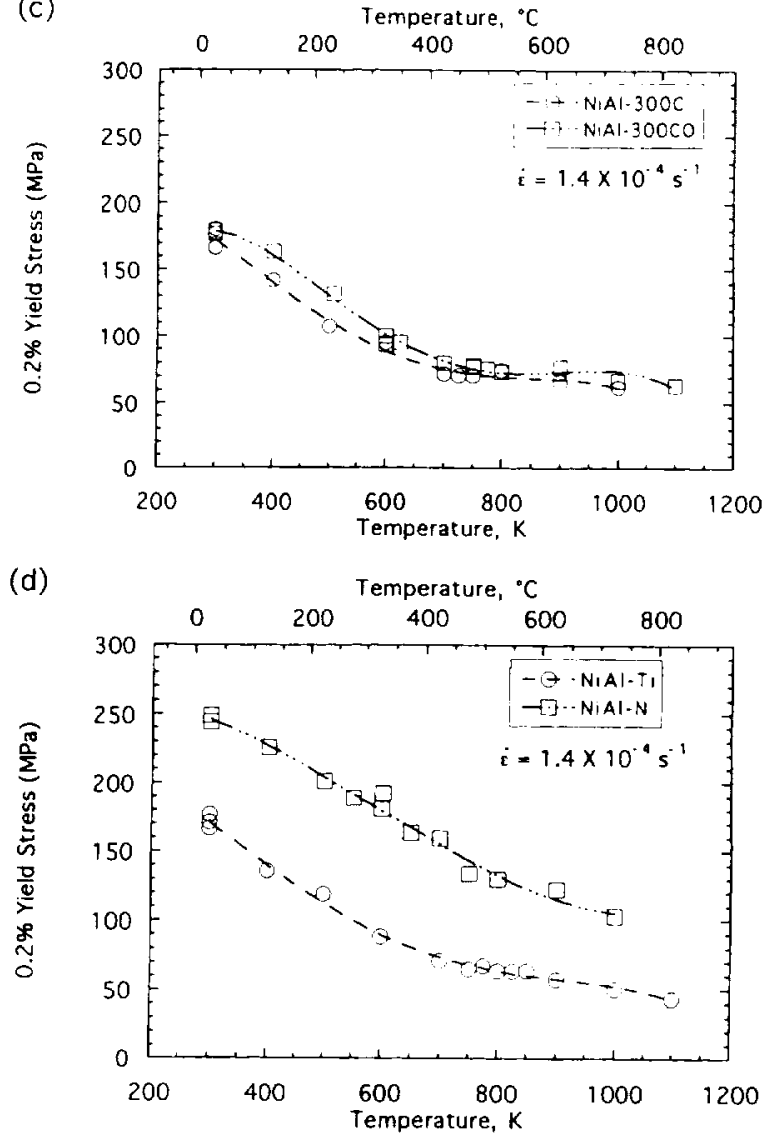

Fig. 1. Temperature dependence of the $0.2 \%$ yield stress for $\mathrm{NiAl}$ alloys: (a) CPNiAl-1 and CPNiAl-2; (b) NiAl-100C and NiAl-$100 \mathrm{CO}$; (c) NiAl-300C and NiAl 300CO; and (d) NiAl-N and NiAl-Ti. 
significant yield points could be recovered in $\mathrm{NiAl}-100 \mathrm{C}$ after annealing for as little as $2100 \mathrm{~s}$ $(35 \mathrm{~min})$ at $622 \mathrm{~K}$. In Fig. 5(b), the kinetics of yield point return after aging at $622 \mathrm{~K}$, measured as the flow stress increment, $\Delta \sigma_{\mathrm{u}}$ (inset in Fig. 5(a)), have been plotted as a function of aging time. In agreement with the data collected for CPNiAl-1 and NiAl-C from previous studies, ${ }^{2-5} \Delta \sigma_{\mathrm{u}}$ initially increases proportionally with aging time, $t$, according to a power law relationship (i.e. $\Delta \sigma_{\mathrm{u}} \propto t^{n}$ ). The strain aging time exponent for $\mathrm{NiAl}-100 \mathrm{C}$ determined by a least squares analysis of the $\Delta \sigma_{\mathrm{u}}$ versus time data was determined to be 0.64 which is close to the theoretical value of $2 / 3$ predicted by Cottrell and Bilby ${ }^{28}$ and is in agreement with the observations for CP-NiAll and $\mathrm{HPNiAl}-\mathrm{C}$ from previous studies. ${ }^{2-5}$

Post-test TEM analysis of the CPNiAl-1 and $\mathrm{NiAl}-100 \mathrm{C}$ (Fig. 6) alloys after deformation at their SRS minima revealed a deformation structure consisting of randomly-distributed $<001>$ dislocations and dislocation debris arranged into coarse tangles and poorly defined cell walls. The cell walls were oriented parallel to the $\langle 110\rangle$ or $\langle 100\rangle$ crystallographic directions indicating some propensity towards localized slip. Similar observations have been

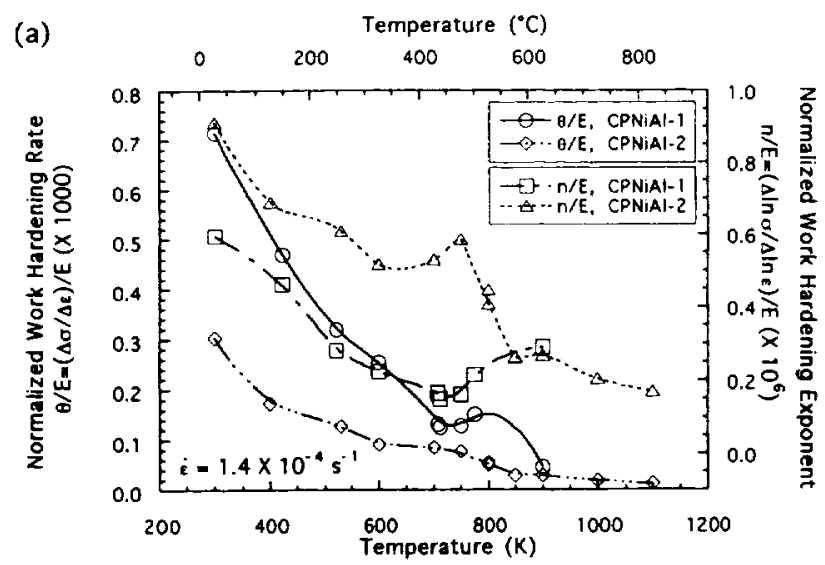

(b)

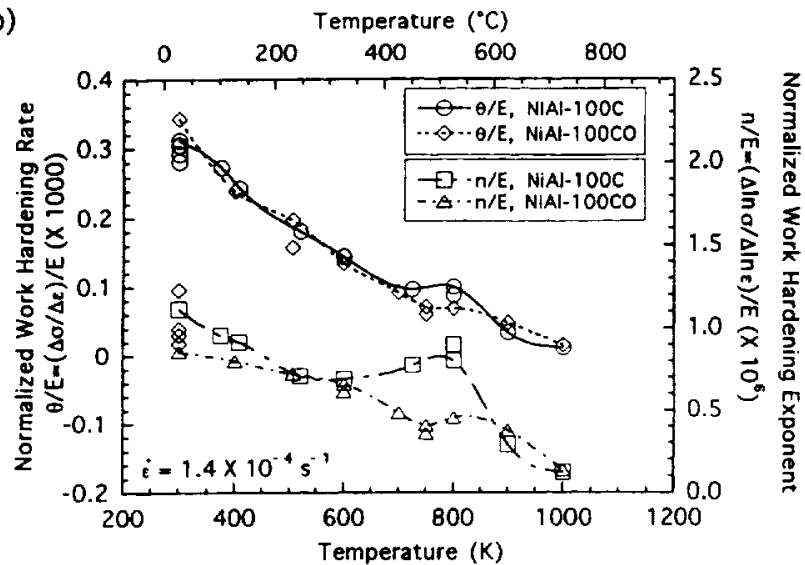

made in single crystal $\mathrm{NiAl}$ alloys. ${ }^{5.10}$ Conversely, in specimens deformed at room temperature, ${ }^{3}$ dislocations were arranged into well developed cellular networks indicating the ease of cross-slip at this temperature. At elevated temperatures, more uniform dislocation distributions are developed due to enhanced relaxation and recovery.

\section{DISCUSSION}

The curves in Figs 1-3 have several common features. (1) In all alloys but $\mathrm{NiAl}-\mathrm{Ti}$ and $\mathrm{NiAl}-\mathrm{N}$, the temperature dependencies of the flow stress and work hardening parameters (i.e. $\theta / E$, and $n / E$ ) increase anomalously in the temperature range $600-850 \mathrm{~K}$. (2) For all of the alloys, the SRSs exhibit distinct minima in the temperature range $750-850 \mathrm{~K}$. (3) The SRS remains positive for all alloys except CPNiAl-1, which exhibited serrated flow behavior in the regime where SRS was negative. These anomalous flow behaviors are generally observed at lower temperatures for carbon doped alloys followed by the conventional purity alloys and then by NiAl-Ti. Similar flow stress peaks and anomalous work hardening param-
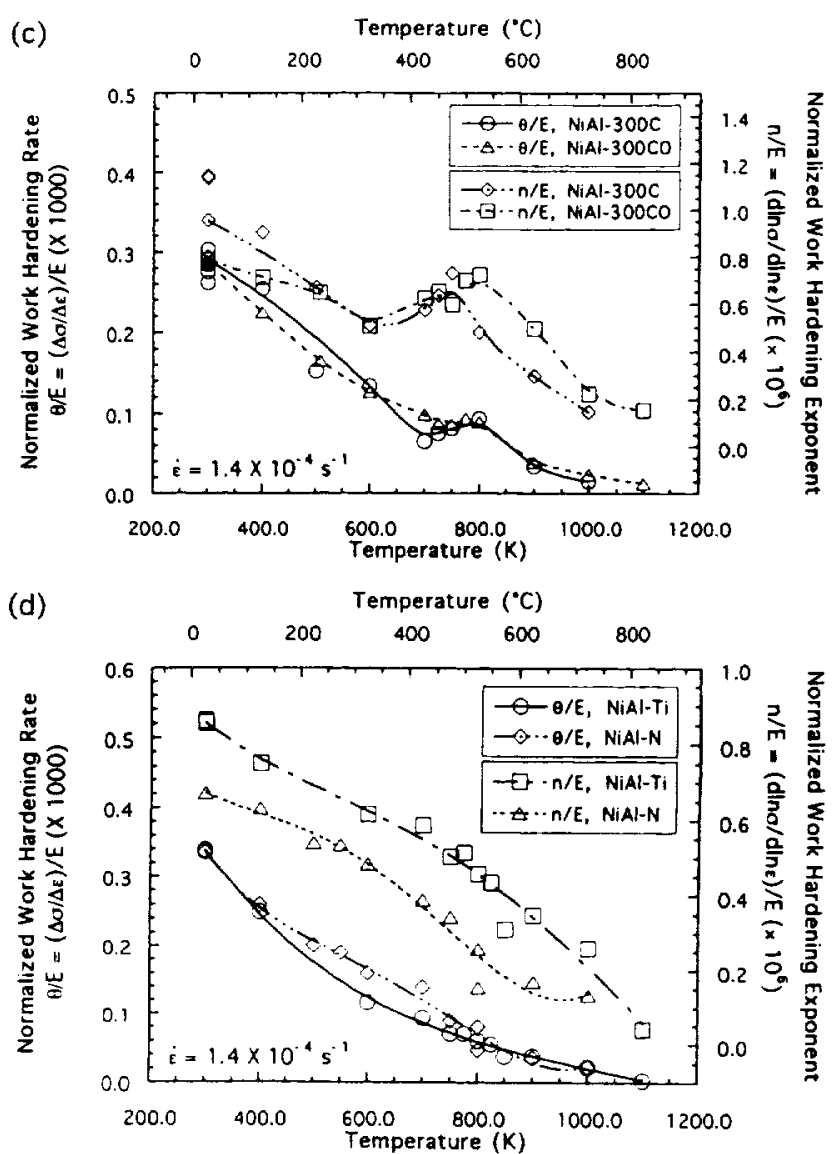

Fig. 2. Temperature dependence of the work hardening rate, $\theta / E=(\Delta \sigma / \Delta \epsilon) E$, and work hardening exponent, $n / E=$ ( $\Delta \ln \sigma / \Delta \ln \epsilon) / E$ : (a) CPNiAl-1 and CPNiAl-2; (b) NiAl-100C and NiAl-100CO; (c) NiAl-300C and NiAl-300CO; and (d) NiAl-N and NiAl-Ti. 
eters have been observed in soft-oriented $\mathrm{NiAl}$ single crystals in this same temperature range as have SRS minima, negative SRS values, and serrated yielding. $5,10,11,13-15$ These anomalies are attributed to the migration of interstitial carbon to dislocations. Confirmation that diffusion of solute atoms toward dislocations is occurring is provided by the static strain aging studies performed in this study and previously. ${ }^{35}$

In the present set of experiments, the flow stress and work hardening anomalies are shifted to higher temperatures compared with the minimum in SRS. This serves as further evidence in favor of DSA. Classical theory ${ }^{29.30}$ dictates that the microscopic mechanism responsible for DSA is the thermally activated motion of dislocations through localized forest obstacles. This type of dislocation motion is characterized by a waiting time, $t_{w}$, during which dislocations temporarily arrested at obstacles in the slip path become pinned by diffusing solute atoms. As a result, the obstacles to dislocation motion become stronger with increasing waiting time (i.e. strength increases with increasing temperature and decreasing strain rate in the DSA regime) resulting in an increased resistance to plastic deformation. Accordingly, SRS reaches a minimum when the time required to pin a dislocation,
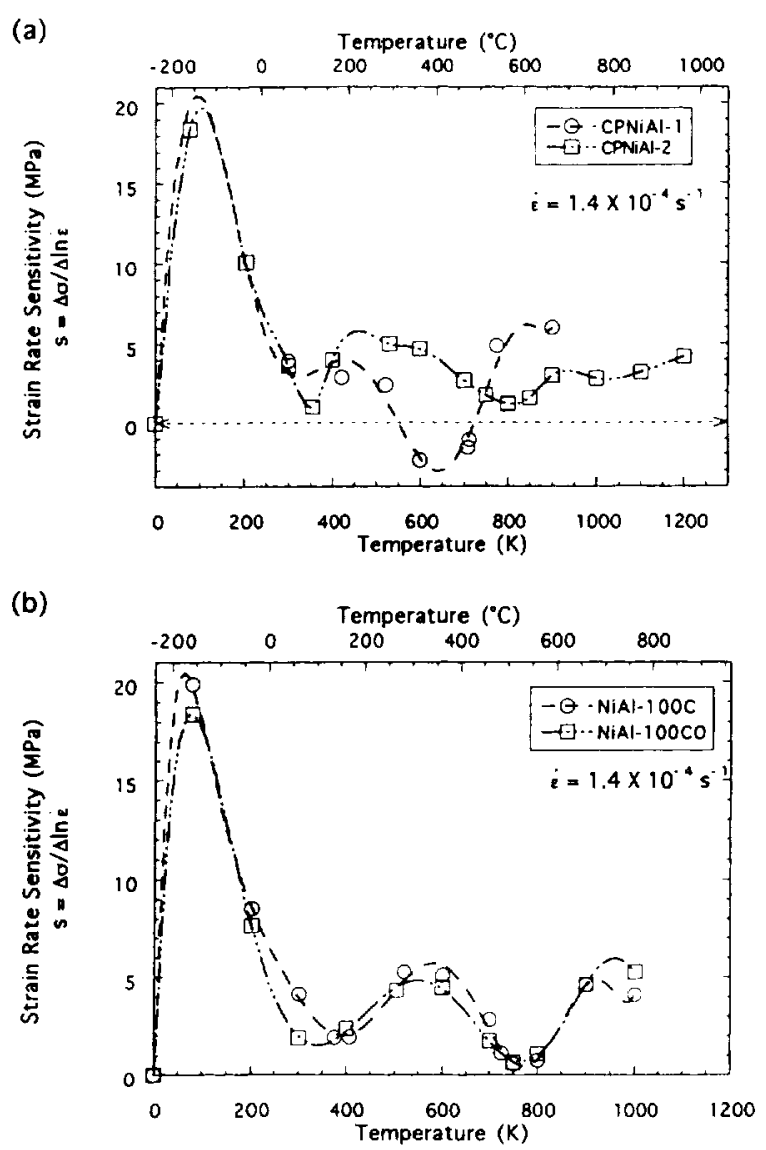

$t_{\mathrm{a}}$, becomes equal to $t_{\mathrm{w}}$. At a given strain rate (i.e. at a fixed $t_{\mathrm{w}}$ ) strengthening saturates when the temperature becomes high enough that $t_{\mathrm{a}}<<t_{\mathrm{w}}$. In other words, maximum strengthening will occur at temperatures higher than the SRS minima.

Normally, the temperatures at which DSA phenomena are observed tend to rise with increasing purity. Thus, the temperatures where SRS minima, flow stress plateaus/peaks, and work hardening anomalies are located should rise with decreasing solute content. Figures 1-3 show that the stress anomalies and SRS minima do indeed occur at lower temperatures for $\mathrm{NiAl}-100 \mathrm{C}$ compared to conventional purity $\mathrm{NiAl}$ alloys. $\mathrm{NiAl}-\mathrm{Ti}$, however, contains just as much $\mathrm{C}$ as $\mathrm{CPNiAl-2}$. Some other interesting observations in $\mathrm{NiAl}-\mathrm{Ti}$ were the lack of a flow stress plateau or anomalous work hardening region and the lack of flow stress transients upon a change in strain rate. It is suggested, therefore, that the gettering of $\mathrm{C}$ by $\mathrm{Ti}$, as reported in ref. 3 , reduces the DSA effects in NiAl-Ti. DSA is not eliminated entirely as evidenced by the SRS minima, either because the maximum solubility of $\mathrm{C}$ in the $\mathrm{Ni}-\mathrm{Al}-\mathrm{Ti}$ alloy is still greater than the concentration required to cause DSA or because there is not enough Ti present to getter all of the $C$.
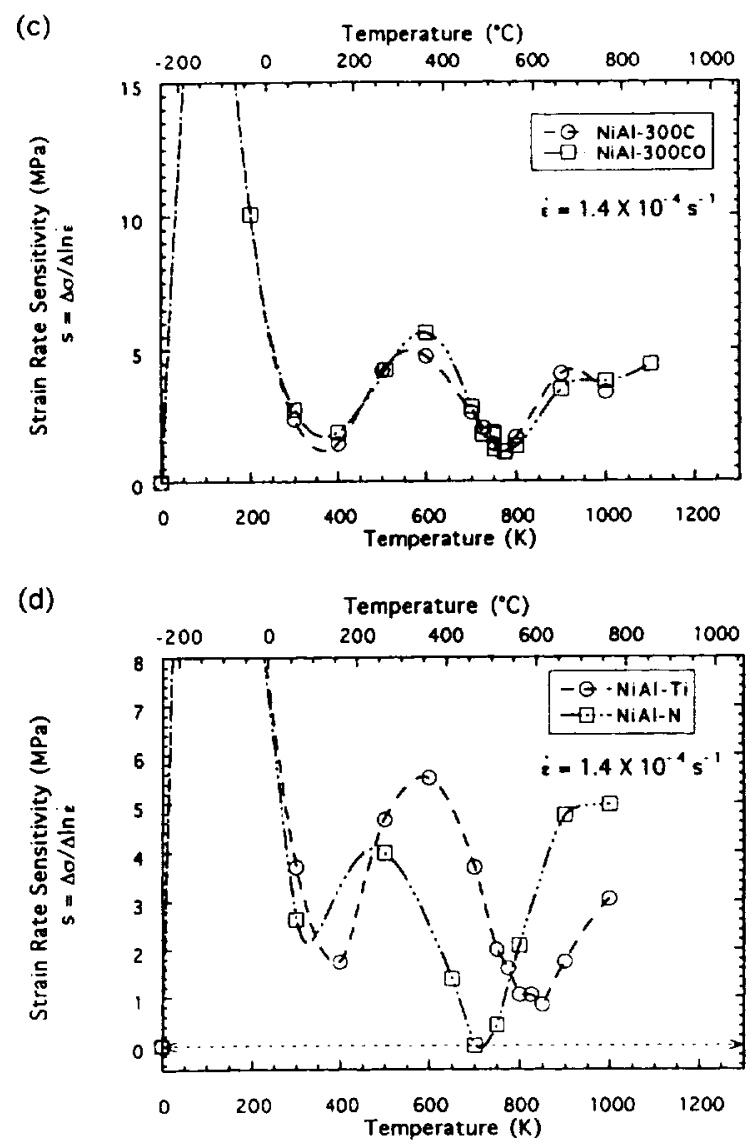

Fig. 3. Temperature dependence of the SRS, $s=\Delta \sigma / \Delta \ln \dot{\epsilon}$ : (a) CPNiAl-1 and CPNiAl-2; (b) NiAl-100C and NiAl-100CO; (c) $\mathrm{NiAl}-300 \mathrm{C}$ and $\mathrm{NiAl}-300 \mathrm{CO}$; and (d) NiAl-N and NiAl-Ti. 
Interestingly, negative SRS and serrated flow was only observed in CPNiAl-1 even though it contained interstitial contents comparable to the other seven alloys used in this study. As a result, all extruded alloys were analyzed for the presence of $\mathrm{Si}$, a common impurity in directionally solidified crystals. The results of these tests are also indicated in Table 1. In CPNiAl-1, residual $\mathrm{Si}$ contents were much higher than those observed in any of the other alloys. This could suggest that silicon, rather than carbon, is the cause for strain aging in NiAl. However,
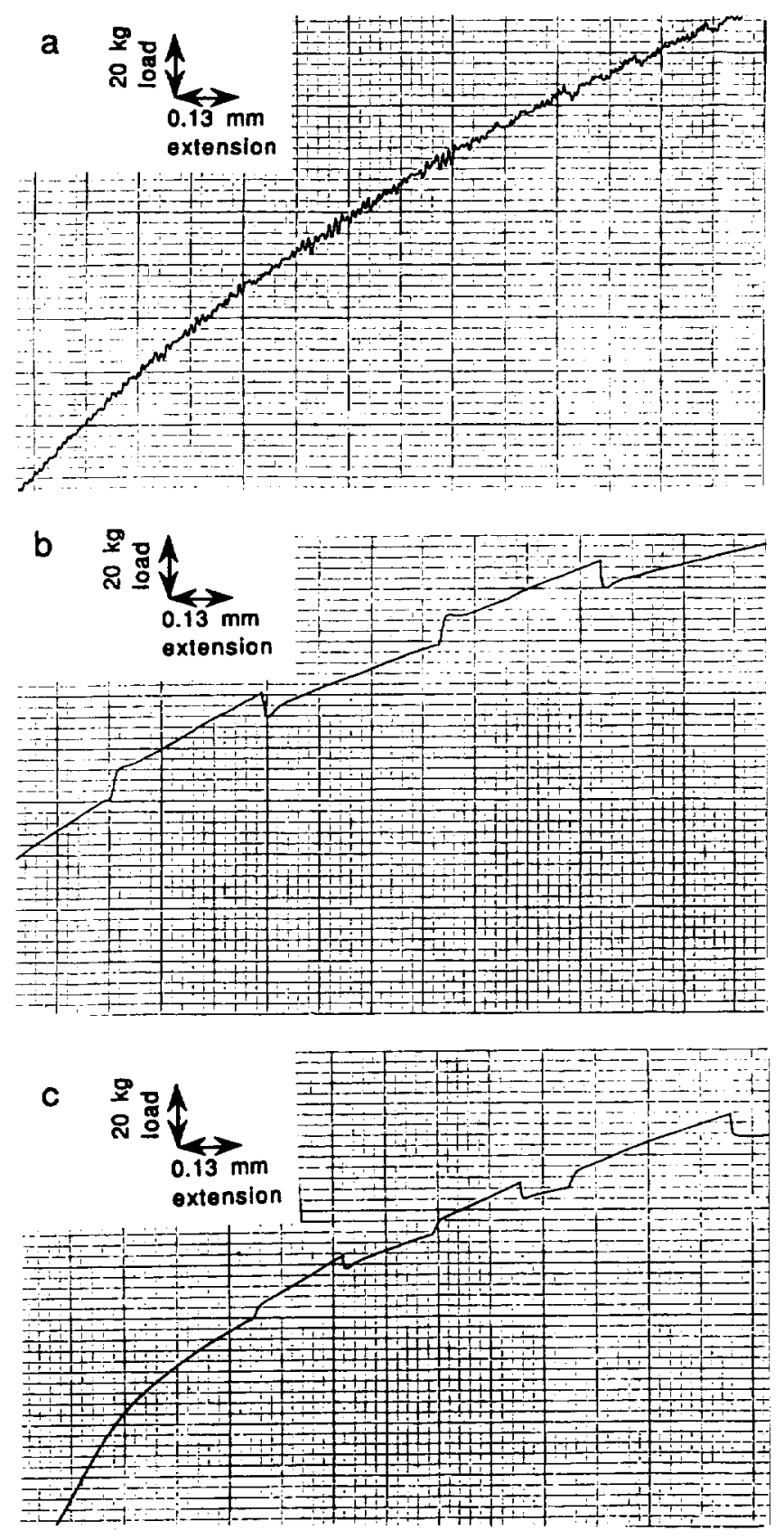

Fig. 4. Examples of serrated flow, stress transients, and the lack of stress transients observed in CPNiAl-1, NiAl-100C, and $\mathrm{NiAl}-\mathrm{Ti}$ during testing near the SRS minimum: (a) serrated load-elongation behavior in CPNiAl-1 at $800 \mathrm{~K}$, (b) stress transients in $\mathrm{NiAl}-100 \mathrm{C}$ at $800 \mathrm{~K}$, and (c) the lack of stress transients in the NiAl-Ti alloy at $725 \mathrm{~K}$. recent investigations by the authors ${ }^{1-5}$ indicated the presence of sharp yield points and broad yield plateaus in high purity C-doped NiAl, CP-NiAl-2, $\mathrm{NiAl}-100 \mathrm{C}$, and $\mathrm{NiAl}-300 \mathrm{C}$ after annealing (i.e. $1100 \mathrm{~K} / 2 \mathrm{~h} / \mathrm{FC}$ ). These four alloys (three of which are listed in Table 1) contain between 0.01 and 0.05 at $\%$ Si. HP-NiAl, NiAl-N and NiAl-Ti, however, exhibit no yield points or plateaus despite the presence of approximately $0.02 \mathrm{at} \% \mathrm{Si}$ in HP-NiAl and NiAl-N. This suggests that it is the higher $\mathrm{C}$ levels, as reported in refs 3 and 5 , rather than the presence of $\mathrm{Si}$, that cause DSA. The results for polycrystalline NiAl-Ti provide further support for this hypothesis. NiAl-Ti contains no Si, exhibits no yield points, but exhibits a dramatic SRS minimum indicative of some DSA at intermediate temperatures. Prior investigations revealed that in this alloy some of the $\mathrm{C}$ is gettered by $\mathrm{Ti}^{\mathrm{1}}{ }^{1.3 .5}$ This indicates that $\mathrm{Si}$ alone cannot be the cause of the DSA observed in NiAl, but serves to indicate that it plays

(a)
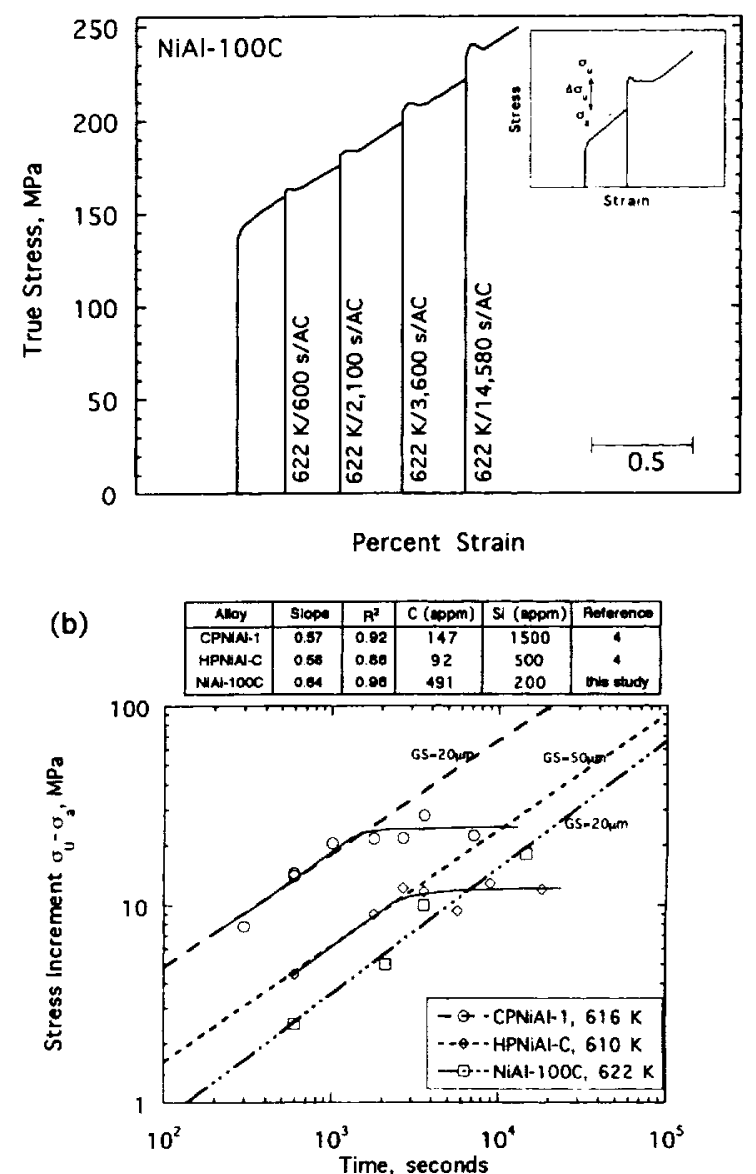

Fig. 5. The kinetics of yield point return for $\mathrm{NiAl}-100 \mathrm{C}$ aged at $622 \mathrm{~K}$. (a) A series of room temperature stress-strain curves for $\mathrm{NiAl}-100 \mathrm{C}$ following multiple strain aging cycles, and (b) temperature dependence of the yield point return for $\mathrm{NiAl}-100 \mathrm{C}$ at $622 \mathrm{~K}$, along with the data for CPNiAl-1 at $616 \mathrm{~K}$ and carbon-doped $\mathrm{NiAl}$ from refs 2.4 and 5 . 
an important role. One possibility is that Si increases the activity of $\mathrm{C}$ in $\mathrm{NiAl}$, resulting in an increased diffusivity of $C$. This suggestion is only speculative, however, and is addressed further in refs 5 and 10.

\section{SUMMARY AND CONCLUSIONS}

The occurrence of serrated yielding in CPNiAl-1, yield points during room temperature testing after annealing, yield stress transients upon changes in strain rate, and the occurrence of yield stress and work hardening anomalies confirm that strain aging does occur in polycrystalline $\mathrm{NiAl}$ alloys. However, evidence for DSA in the alloys other than CPNiAl-1 is more subtle and is indicated predominantly by SRS
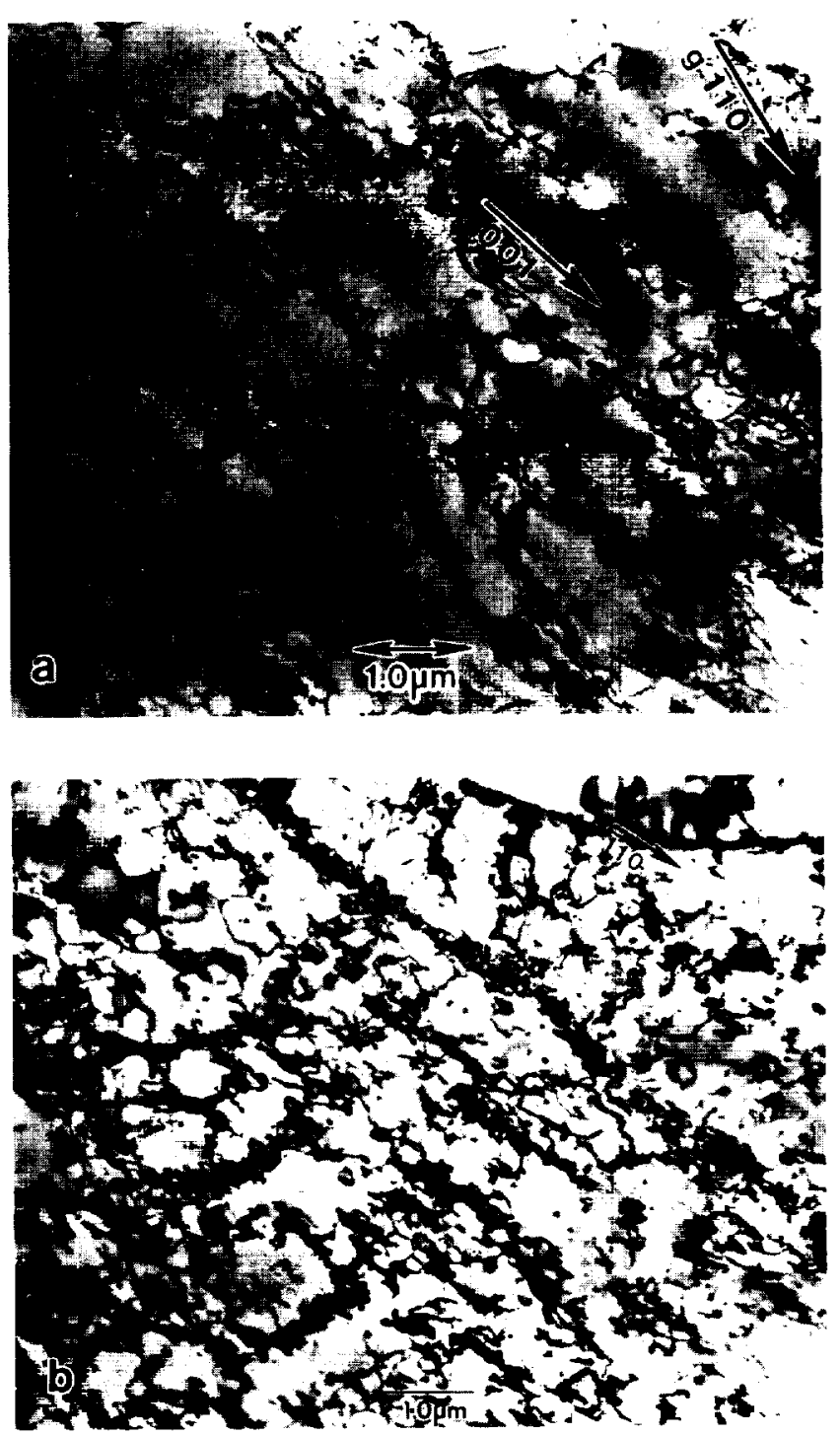

Fig. 6. BFTEM of dislocation structures observed in CPNiAl-1 and $\mathrm{NiAl}-100 \mathrm{C}$ following deformation at their respective SRS minimums. (a) CPNiAl-1 following 3\%, deformation at $700 \mathrm{~K}$, and (b) NiAl- $100 \mathrm{C}$ after $11.5 \%$ deformation at $800 \mathrm{~K}$ minima and anomalous yield strength-temperature behavior.

Preliminary analysis indicates that residual $\mathrm{Si}$ impurities in addition to $C$ can play a significant role in DSA, and that dilute quantities of reactive metals can reduce the effects of DSA via a gettering mechanism.

\section{ACKNOWLEDGEMENTS}

Helpful discussions with R. E. Reed-Hill, A. J. Duncan and V. I. Levit are gratefully acknowledged. MLW and MJK express their appreciation for the financial and technical support of the NASA-Lewis Research Center under grant number NGT3-2958.

\section{REFERENCES}

1. Weaver, M. L.. Levit. V.. Kaufman, M. J. \& Noebe. R. D., in High-Temperature Ordered Intermetallic Allows $\mathrm{Vl}$. eds J. A. Horton. I. Baker. S. Hanada. R. D. Noebe \& D. S. Schwartz. Materials Research Society. Pittsburgh, PA. 1995. vol. 364, p. 425.

2. Weaver. M. L. Noebe, R. D., Lewandowski, J. J., Oliver. B. F. \& Kaufman. M. J., Mater. Sci. Eng., A192/193 (1995) 179.

3. Weaver, M. L., Noebe, R. D., Lewandowski. J. J., Oliver B. F. \& Kaufman, M. J., Intermetallics, 4 (1996) 533.

4. Weaver, M. L., Kaufman, M. J. \& Noebe, R. D., Intermetallics, 4 (1996) 121.

5. Weaver, M. L., Investigation of Strain Aging in the Ordered Intermetallic Compound $\beta$-NiAl. PhD Dissertation. University of Florida. 1995.

6. Lubahn, J. D.. Trans. ASM, 44 (1952) 643.

7. Rodriquez. P.. Bull. Mater. Sci. India) 6 (1984) 653.

8. Robinson. J. M. \& Shaw, M. P., Int. Mater. Re'v. 39 (1994) 113.

9. Reed-Hill, R. E., Rev. High Temp. Mat., 2 (1974) 217

10. Weaver. M. L., Noebe, R. D. \& Kaufman, M. J., Me'lall. Mater. Trans. A, (1996) in press.

11. Brzeski, J. M., Hack. J. E., Darolia, R. \& Field. R. D.. Mater. Sci. Eng., A170 (1993) 11

12. Brzeski, J. M., Hack. J. E. \& Darolia. R., in High-Temperature Ordered Intermetallic Alloys VI. eds J. A. Horton. I. Baker, S. Hanada. R. D. Noebe \& D. S. Schwartz. Materials Research Socicty, Pitsburgh, PA. 1995. vol. 364. p. 419.

13. Hack. J. E., Brzeski, J. M. \& Darolia, R., Scripfa Mo'lall. Mater. 27 (1992) 1259.

14. Hack, J. E., Brzeski. J. M., Darolia, R. \& Field. R. D.. in High-Temperature Ordered Intermetallics $V$. eds I. Baker. R. Darolia, J. D. Whittenberger \& M. H. Yoo, Materials Research Society, Pittsburgh, PA. 1993. vol. 288. p. 1197.

15. Hack, J. E., Brzeski, J. M. \& Darolia. R., Mater. Sci. Eng.. A 192/193 (1995) 268.

16. Pascoe, R. T. \& Newey, C. W. A., Metall. Sci. J., 2 (1968) 138.

17. Pascoc, R. T. \& Newey. C. W. A.. Metall. Sci. J., 5 (1971) 50 .

18. Lautenschlager. E. P.. Kiewit. D. A. \& Brittain. J. O., Trums. Metall. Soc, AIME, 233 (1965) 1297.

19. Miracle. D. B., Acta Motall. Mater. 41 (1993) 649.

20. Noebe, R. D., Bowman, R. R. \& Nathal, M. V., Int. Mater. Rev.. 38 (1993) 193. 
21. Noebe, R. D., Bowman, R. R. \& Nathal, M. V., in Physical Metallurgy and Processing of Intermetallic Compounds, eds N. S. Stoloff and V. K. Sikka, Chapman \& Hall. New York. NY, 1995, pp. 212-250.

22. Weaver, M. L., Kaufman, M. J. \& Noebe, R. D., Scripra Metall. Mater., 29 (1993) 1113.

23. Dieter, G. E., Mechanical Metallurgy, McGraw-Hill, New York, 1986

24. Harmouche, M. R. \& Wolfenden, A., J. Test. Eval., 15 (1987) 101

25. Moose, C. A., Interfacial Shear Studies of Sapphire FiberReinforced Nickel Aluminide Matrix Composites, MS Thesis,
Pennsylvania State University, 1991.

26. Kitano, K. \& Pollock, T. M., in Structural Intermetallics, eds R. Darolia, J. J. Lewandowski, C. T. Liu, P. L. Martin, D. B. Miracle and M. V. Nathal, The Minerals, Metals and Materials Society, Warrendale, PA, 1993. p. 591.

27. Kitano, K., Pollock, T. M. \& Noebe, R. D., Scripta Metall Mater.. 31 (1994) 397.

28. Cottrell, A. H. \& Bilby, B. A., Proc. Phys. Soc. London. A62 (1949) 49.

29. Kubin, L. P. \& Estrin, Y., J. Phys. III, 1 (1991) 929.

30. McCormick, P. G., Acta Metall, 20 (1972) 351. 